Published in final edited form as:

J Am Chem Soc. 2006 November 29; 128(47): 15084-15085. doi:10.1021/ja065907x.

\title{
The Total Synthesis of Moenomycin A
}

\author{
James G. Taylor ${ }^{\dagger}$, Xuechen $\mathrm{Li}^{\dagger}$, Markus Oberthür ${ }^{\dagger}$, Wenjiang Zhu ${ }^{\dagger}$, and Daniel E. Kahne ${ }^{\dagger, \ddagger^{*}}$ \\ Department of Chemistry and Chemical Biology, Harvard University, Cambridge, MA 02138 \\ Department of Biological Chemistry and Molecular Biology, Harvard Medical School, Boston, MA 02115
}

\begin{abstract}
Moenomycin A is the only known natural antibiotic that inhibits bacterial cell wall synthesis by binding to the transglycosylases that catalyze formation of the carbohydrate chains of peptidoglycan. We report here the total synthesis of moenomycin A using the sulfoxide glycosylation method. A newly discovered byproduct of sulfoxide reactions was isolated that resulted in substantial loss of the glycosyl acceptor. A general method to suppress this byproduct was introduced, which enabled the glycosylations to proceed efficiently. The inverse addition protocol for sulfoxide glycosylations also proved essential in constructing some of the glycosidic linkages. The synthetic route is flexible and will allow for derivatives to be constructed to further analyze moenomycin A's mechanism of action.
\end{abstract}

Moenomycin A (1) is a potent antibiotic that inhibits bacterial cell wall synthesis by binding to the transglycosylases that catalyze formation of the carbohydrate chains of peptidoglycan. ${ }^{1}$ Moenomycin is the only natural product inhibitor known to directly bind to these enzymes. Its distinctive mechanism of action is matched by its unusual structure. Moenomycin A consists of a highly functionalized pentasaccharide attached via a unique phosphoglycerate linkage to a polyprenyl chain. Many approaches to the synthesis of moenomycin fragments and derivatives have been reported over the past 30 years, primarily by Welzel and coworkers, but the total synthesis of moenomycin A has not been accomplished. ${ }^{2}$ We report here the first total synthesis of moenomycin A.

The moenomycin pentasaccharide presents a number of synthetic challenges. Electronwithdrawing groups on several of the monosaccharides make them poor glycosyl donors and/ or acceptors. Many of the glycosidic bonds must also be formed to sterically hindered alcohols. For example, the $\mathrm{B}$ ring galacturonamide is a deactivated donor due to the electron-withdrawing $\mathrm{C} 6$ position ${ }^{3}$ and the $\mathrm{C} 4$ hydroxyls of the $\mathrm{C}$ and $\mathrm{E}$ rings of moenomycin are sterically hindered and particularly unreactive in glycosylation reactions. ${ }^{4}$ The stability of the diverse functional groups is also a concern. The $\mathrm{F}$ ring contains both an amide and a carbamate, which are potentially reactive under glycosylation conditions, and the A ring is sensitive to both oxidation $^{5}$ and hydrogenation 6 procedures. 


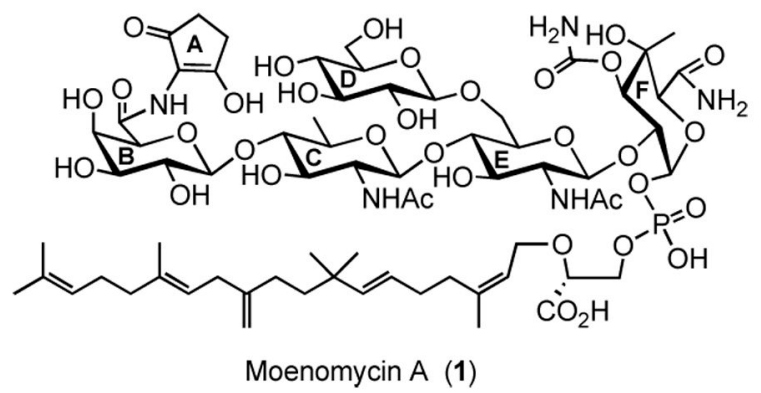

Our synthetic approach involved constructing the BCEF tetrasaccharide from the $\mathrm{BC}$ and $\mathrm{EF}$ disaccharide fragments, followed by attachment of the $\mathrm{D}$ ring. The synthesis of the protected BCEF tetrasaccharide $\mathbf{1 0}$ is shown in Scheme 1. Because preliminary investigations into the synthesis of the $\mathrm{BC}$ disaccharide revealed that the A ring would not survive the glycosylation conditions, the $\mathrm{C} 6$ position of the $\mathrm{B}$ ring $\mathbf{2}$ was protected as an ester to allow for late stage attachment of the A ring. The $\mathrm{C} 2$ amine of the $\mathrm{C}$ ring acceptor $\mathbf{3}$ was protected with a tetrachlorophthaloyl (TCP) group 7 as reports have demonstrated that this bulky protecting group enables regioselective glycosylation at $\mathrm{C} 4$ in the presence of an unprotected $\mathrm{C} 3$ hydroxyl. 8 In addition, the TCP protecting group allows for neighboring group participation at $\mathrm{C} 2$, providing $\beta$-stereochemical control during formation of the subsequent $\mathrm{CE}$ glycosidic linkage. The glycosylation of $\mathbf{2}$ with $\mathbf{3}$ afforded BC disaccharide $\mathbf{6}$ regioselectively and stereoselectively in $75 \%$ yield using the standard sulfoxide glycosylation protocol, which involves adding triflic anhydride to the glycosyl sulfoxide prior to adding the acceptor 9 . Disaccharide 6 was then oxidized to sulfoxide 7.

Unlike the $\mathrm{BC}$ linkage, none of the other glycosidic bonds were formed using the standard glycosylation conditions. In the case of the EF $\beta-1,2$ linkage, we observed that benzenesulfinic ester formation on the $\mathrm{C} 2$ hydroxyl of $\mathrm{F}$ ring $\mathbf{5}$ led to significant loss of the glycosyl acceptor. $10 \mathrm{PhSOTf}$ is generated during sulfoxide glycosylations and is known to activate glycosyl sulfoxides. ${ }^{11}$ Benzenesulfinic ester formation was presumed to be a downstream byproduct resulting from the reaction of PhSOTf with glycosyl sulfoxides. Using 4-allyl-1,2dimethoxybenzene (ADMB) to scavenge PhSOTf ${ }^{12}$ and changing the order of reagent addition during the reaction (inverse addition) ${ }^{13}$ suppressed benzenesulfinic ester formation and the EF disaccharide 8 was obtained in $84 \%$ yield. The 4,6-( $p$-methoxylbenzylidene) group was then regioselectively opened ${ }^{14}$ to afford 9 .

Coupling of the $\mathrm{EF}$ and $\mathrm{BC}$ disaccharide fragments also required the inverse addition protocol because the $\mathrm{BC}$ glycosyl donor decomposed under the standard activation conditions. Inverse addition decreases decomposition because the oxacarbenium ion is generated slowly in the presence of the acceptor alcohol, which traps the reactive intermediate before it reacts with other species. ${ }^{13}$ Thus, when donor 7 was added to a solution containing triflic anhydride and acceptor $\mathbf{9}$, tetrasaccharide $\mathbf{1 0}$ was obtained stereoselectively in 50\% yield. The free hydroxyl on the $\mathrm{C}$ ring was then acetylated followed by removal of the PMB ether with DDQ to give 11 (Scheme 2).

The final glycosylation involved forming a $\beta-1,6$ linkage between a D ring sulfoxide and tetrasaccharide 11. To avoid introducing a hindered, electron-withdrawing ester group on the $\mathrm{C} 2$ position of the $\mathrm{D}$ ring donor, we chose to form this glycosidic linkage with solvent control using propionitrile, which is known to give high $\beta$-stereoselectivity in glycosylations. ${ }^{9,15} \mathrm{As}$ before, benzenesulfinic ester byproducts dominated the reaction in the absence of a PhSOTf scavenger. When the reaction was carried out using the scavenger ADMB and inverse addition, pentasaccharide $\mathbf{1 2}$ was obtained in $76 \%$ yield with complete $\beta$-stereoselectivity. 
Completion of the moenomycin pentasaccharide synthesis required protecting group removal and installation of the 2-amino-cyclopentane-1,3-dione (A ring) chromophore and $\mathrm{F}$ ring amide and carbamate. Selective conversion of the phenyl ester and phenyl carbonate of $\mathbf{1 2}$ into the desired carboxamide and carbamate, respectively, was accomplished using $\mathrm{NH}_{3}$ in IPA/ $\mathrm{CH}_{2} \mathrm{Cl}_{2}$. The TCP protecting groups were then removed with ethylenediamine and the liberated amines were acylated in situ to give 13. Hydrogenation of the benzyl groups using $\mathrm{Pd}(\mathrm{OH})_{2} /$ $\mathrm{C}$ in $\mathrm{MeOH}$ and acetylation of the hydroxyls gave 14. Removal of the TMSE groups with $\mathrm{BF}_{3},{ }^{16}$ followed by coupling of the A ring ${ }^{17}$ using HATU, and global deprotection with $\mathrm{NaOH}$ afforded the fully deprotected pentasaccharide $\mathbf{1 5}$. The identity of $\mathbf{1 5}$ was confirmed by correlation with the natural pentasaccharide obtained through degradation of moenomycin A. Peracetylation of $\mathbf{1 5}$ followed by selective deprotection of the anomeric acetate with hydrazine gave 16. Coupling of $\mathbf{1 6}$ to the moenocinyl glycerate unit and deprotection, using our published procedure $^{18}$, afforded moenomycin A (1).

This synthesis of moenomycin A is both efficient and flexible, allowing for variants of the antibiotic to be constructed in order to probe its mechanism of action. Each glycosidic linkage was synthesized stereoselectively using the sulfoxide glycosylation reaction. Two sets of reaction conditions were employed depending on the reactivity of the donor-acceptor pairs. The sulfoxide activation conditions described here, along with those described previously 19 , should enable the construction of most glycosidic linkages.

\section{Supplementary Material}

Refer to Web version on PubMed Central for supplementary material.

\section{Acknowledgement}

Support for this work was provided by the National Institutes of Health (Grant GM66174).

\section{References}

1. van Heijenoort J. Glycobiology 2001;11:25R-36R.and references therein

2. For a review of previous synthetic efforts toward moenomycin A see: Welzel P. Chem. Rev 2005;105:4610-4660. [PubMed: 16351056]

3. Müller T, Schneider R, Schmidt RR. Tetrahedron Lett 1994;35:4763-4766.

4. (a) Paulsen H. Angew. Chem., Int. Ed. Engl 1982;21:155-173. (b) Crich D, Dudkin V. J. Am. Chem. Soc 2001;123:6819-6825. [PubMed: 11448186]

5. Welzel P, Kunisch F, Kruggel F, Stein H, Scherkenbeck J, Hiltmann A, Duddeck H, Müller D, Maggio JE, Fehlhaber HW, Seibert G, van Heijenoort Y, van Heijenoort J. Tetrahedron 1987;43:585-598.

6. Marzian S, Happel M, Wagner U, Müller D, Welzel P, Fehlhaber HW, Stärk A, Schütz HJ, Markus A, Limbert M, van Heijenoort Y, van Heijenoort J. Tetrahedron 1994;50:5299-5308.

7. (a) Debenham JS, Madsen R, Roberts C, Fraser-Reid B. J. Am. Chem. Soc 1995;117:3302-3303. (b) Castro-Palomino JC, Schmidt RR. Tetrahedron Lett 1995;36:5343-5346.

8. (a) Lay L, Manzoni L, Schmidt RR. Carbohyd. Res 1998;310:157-171. (b) Ellervik U, Magnusson G. J. Org. Chem 1998;63:9314-9322.

9. Kahne D, Walker S, Cheng Y, Van Engen D. J. Am. Chem. Soc 1989;111:6881-6882.

10. For a discussion of benzenesulfinic ester formation see: TaylorJGPhD Thesis2006Harvard University 11. Crich D, Sun S. J. Am. Chem. Soc 1997;119:11217-11223.

12. Gildersleeve J, Smith A, Sakurai K, Raghavan S, Kahne D. J. Am. Chem. Soc 1999;121:6176-6182.

13. Gildersleeve J, Pascal RAJ, Kahne D. J. Am. Chem. Soc 1998;120:5961-5969.

14. Hernández-Torres JM, Achkar J, Wei A. J. Org. Chem 2004;69:7206-7211. [PubMed: 15471470]

15. Schmidt RR, Behrendt M, Toepfer A. Synlett 1990;11:694-696. 
16. Jansson K, Ahlfors S, Frejd T, Kihlberg J, Magnusson G, Dahmén J, Noori G, Stenvall K. J. Org. Chem 1988;53:5629-5647.

17. Ebenezer WJ. Synthetic Commun 1991;21:351-358.

18. Adachi M, Zhang Y, Leimkuhler C, Sun B, LaTour J, Kahne DD. J. Am. Chem. Soc 2006; 128:XXXXXXXX.

19. Crich D, Lim LBL. Org. React 2004;64:115-251. 

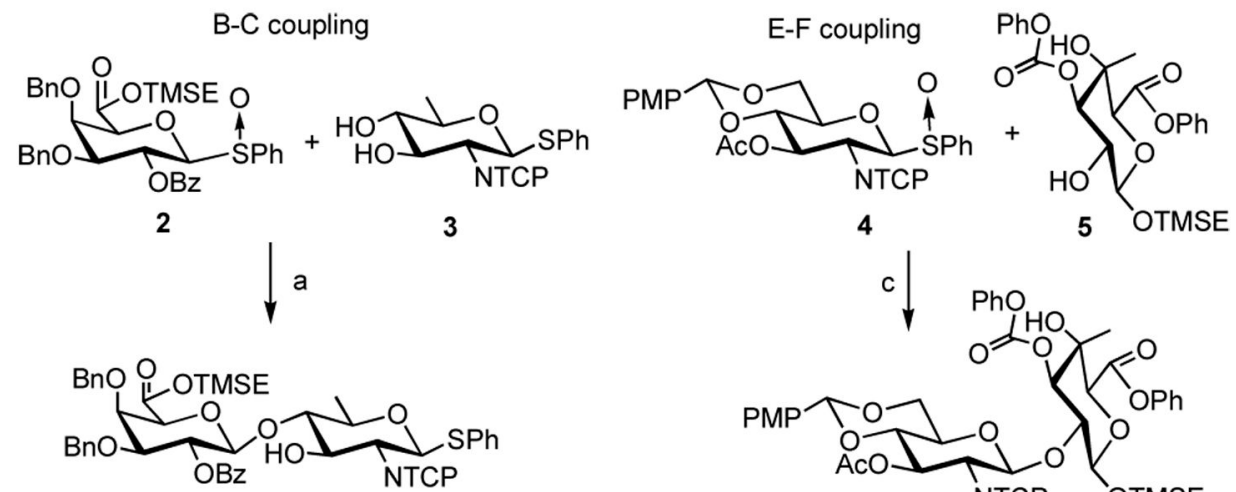

6
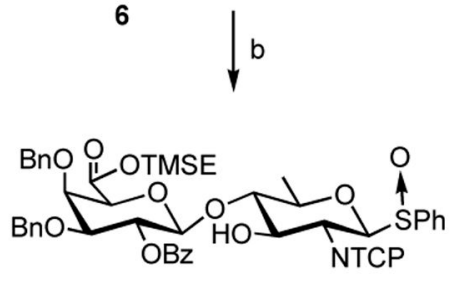

7

BC-EF coupling
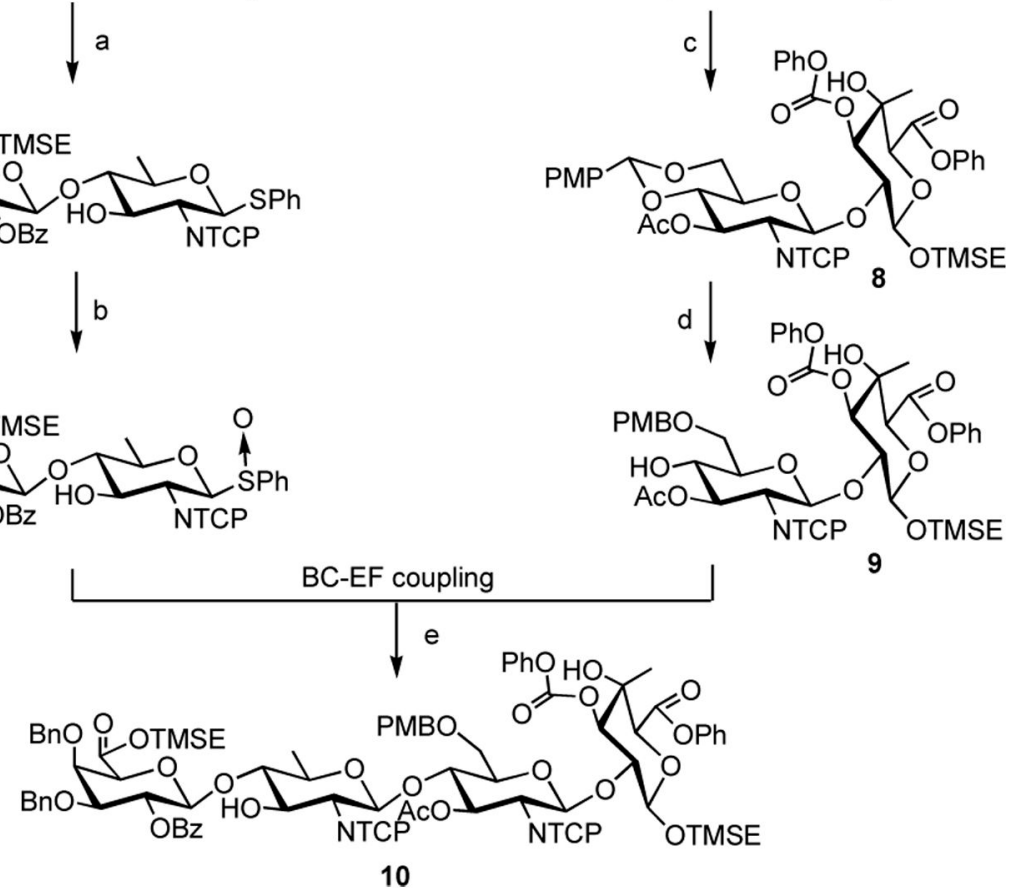

Scheme 1. Construction of BC, EF and BCEF oligosaccharidesa

a Conditions: (a) $\mathrm{Tf}_{2} \mathrm{O}$, DTBMP, ADMB, $\mathrm{CH}_{2} \mathrm{Cl}_{2},-78$ to $0{ }^{\circ} \mathrm{C}, 75 \%$; (b) $\mathrm{mCPBA} \mathrm{CH}_{2} \mathrm{Cl}_{2}$, -78 to $0{ }^{\circ} \mathrm{C}, 70 \%$; (c) $\mathrm{Tf}_{2} \mathrm{O}$, DTBMP, ADMB, $\mathrm{CH}_{2} \mathrm{Cl}_{2},-42{ }^{\circ} \mathrm{C}, 84 \%$; (d) $\mathrm{Bu}_{2} \mathrm{BOTf}, \mathrm{BH}_{3} \cdot \mathrm{THF}$, THF, $-60{ }^{\circ} \mathrm{C}, 83 \%$; (e) $\mathrm{Tf}_{2} \mathrm{O}$, DTBMP, ADMB, $\mathrm{CH}_{2} \mathrm{Cl}_{2},-60{ }^{\circ} \mathrm{C}, 50 \%$. DTBMP = 2,6-ditert-butyl-4-methylpyridine, $\mathrm{ADMB}=4$-allyl-1,2-dimethoxybenzene 


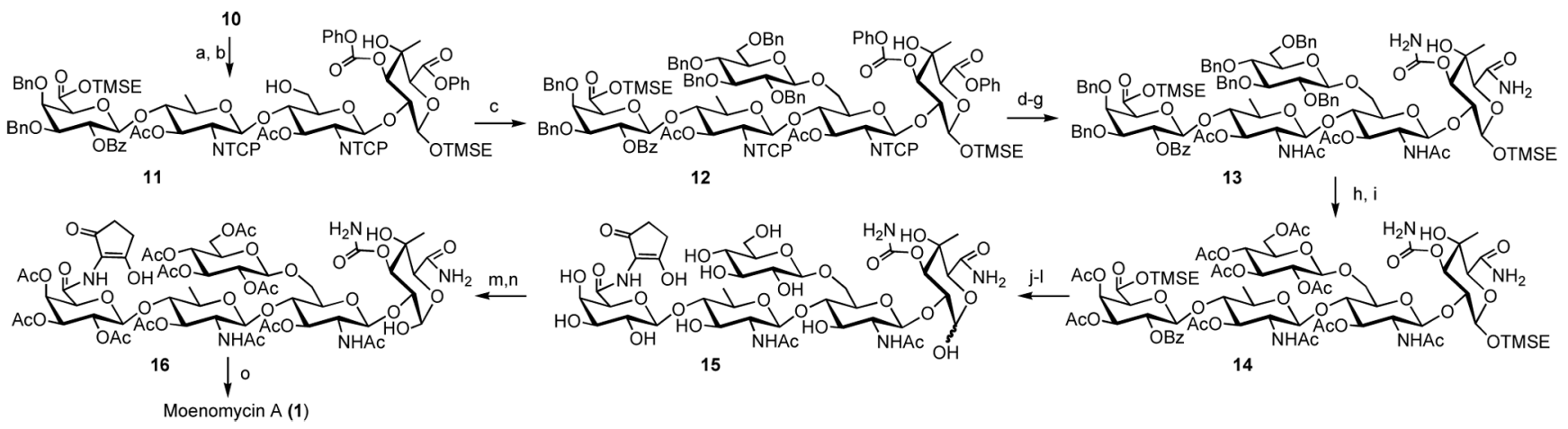

Scheme 2. Completion of the synthesisa

${ }^{a}$ Conditons: (a) $\mathrm{Ac}_{2} \mathrm{O}, \mathrm{Py}, 93 \%$; (b) DDQ, pH 7 buffer, 79\%; (c) Phenyl 2,3,4,6-tetra- $\mathrm{O}$ benzyl-1-thio- $\beta$-D-glucopyranoside $S$-Oxide, $\mathrm{Tf}_{2} \mathrm{O}$, DTBMP, ADMB, propionitrile, $-78^{\circ} \mathrm{C}$, $76 \%$; (d) $\mathrm{NH}_{3}$ in IPA/ $\mathrm{CH}_{2} \mathrm{Cl}_{2}$; (e) ethylenediamine, $\mathrm{EtOH}, 6{ }^{\circ} \mathrm{C}$ (f) $\mathrm{Ac}_{2} \mathrm{O}, \mathrm{EtOH},(\mathrm{g}) \mathrm{Ac}_{2} \mathrm{O}$, Py, $66 \%$ over 4 steps; (h) $\mathrm{H}_{2}, \mathrm{Pd}(\mathrm{OH})_{2} / \mathrm{C}, \mathrm{MeOH}$; (i) $\mathrm{Ac}_{2} \mathrm{O}$, Py, $63 \%$ over 2 steps; (j) $\mathrm{BF}_{3} \cdot \mathrm{Et}_{2} \mathrm{O}, \mathrm{CH}_{2} \mathrm{Cl}_{2}, 97 \%$; (k) 2-amino-cyclopentane-1,3-dione, HATU, DIPEA, $\mathrm{CH}_{2} \mathrm{Cl}_{2} /$ DMF, 55\%; (l) NaOH, THF, 80\%; (m) $\mathrm{Ac}_{2} \mathrm{O}$, Py, 78\%; (n) $\mathrm{H}_{2} \mathrm{NNH}_{2}-\mathrm{HOAc}, 53 \%$; (o) i. $2-$ Chloro-1,3,2-benzodioxaphosphorin-4-one, $85 \%$; ii. (R)-3-hydroxy-2-[(2Z,6E, 13E)-3,8,8,14,18-pentamethyl-11-methylene-nonadeca-2,6,13,17-tetraen-1-yloxy] propanoate, 1-adamantanecarbonyl chloride, $\mathrm{NMM} / \mathrm{CCl}_{4} / \mathrm{Py} / \mathrm{CH}_{3} \mathrm{CN} / \mathrm{H}_{2} \mathrm{O}$ (1:2.5:6:1:1), $62 \%$; iii. $0.1 \mathrm{~N} \mathrm{LiOH}, \mathrm{THF} / \mathrm{H}_{2} \mathrm{O}(1: 1)$, then $\mathrm{AcOH}, 47 \% .18$ 